\title{
An NF- $\kappa$ B-Like Transcription Factor in Axoplasm is Rapidly Inactivated after Nerve Injury in Aplysia
}

\author{
Michael Povelones, ${ }^{1}$ Kathy Tran, ${ }^{2}$ Dimitris Thanos, ${ }^{2}$ and Richard T. Ambron ${ }^{1}$ \\ ${ }^{1}$ Departments of Anatomy and Cell Biology and ${ }^{2}$ Biochemistry and Molecular Biophysics, College of Physicians and \\ Surgeons of Columbia University, New York, New York 10032
}

\begin{abstract}
We found a protein in Aplysia neurons that has many characteristics of the transcription factor NF- $\kappa \mathrm{B}$. Thus, the protein recognized a radiolabeled probe containing the $\kappa \mathrm{B}$ sequence from the human interferon- $\beta$ gene enhancer element (PRDII), and the binding was not affected by PRDIV, an ATF-2 enhancer sequence from the same gene. Binding was efficiently inhibited, however, by nonradioactive oligonucleotides containing $\mathrm{H} 2$, the $\kappa \mathrm{B}$ site from the major histocompatibility complex I gene promotor. In addition, recombinant mammalian $I_{\kappa} \mathrm{B}-\alpha$, which associates specifically with the P65 subunit of NF- $\kappa \mathrm{B}$, inhibited the binding to the PRDIl probe in a dose-dependent manner. The nuclear form of the Aplysia protein was constitutively active. Axoplasm, however, contained the constitutively active
\end{abstract}

form as well as a latent form. The latter was activated by treatment with deoxycholate under the same conditions as mammalian NF- $\kappa \mathrm{B}$. Based on these findings, we believe the protein to be a homolog of NF- $\kappa$ B. To investigate the role of apNF $-\kappa \mathrm{B}$ in the axon, we crushed the peripheral nerves to the body wall. Surprisingly, there was a rapid loss of apNF- $\kappa \mathrm{B}$ binding at the crush site and, within $15 \mathrm{~min}$, as far as $2.5 \mathrm{~cm}$ along the axon. In contrast, exposing either the intact animal or the nervous system in situ to levels of 5-HT that induce synaptic facilitation did not affect apNF- $\kappa \mathrm{B}$ activity.

Key words: NF-кB; axon injury; transcription factor; axoplasm; DNA binding; injury signal; nuclear localization signal
Nerve injury initiates changes in transcription and translation that can culminate in the regeneration of the damaged axon (Lieberman, 1971; Skene, 1989; Fawcett and Keynes, 1990; Titmus and Faber, 1990). How the cell body is informed that its axon has been damaged is not well understood, and identifying the signals that convey this information would be a significant advance in the quest to facilitate nerve repair. Molecular signals of injury can be divided into two classes (Skene, 1989; Clatworthy and Walters, 1994; Walters and Ambron, 1995): "negative" signals, which originate from target tissues, and "positive" signals, which are retrogradely transported from the site of injury back to the nucleus. Some positive signals are intrinsic to axoplasm (Ambron et al., 1996), whereas others are extrinsic, i.e., derived from glial cells at the site of the lesion. Interestingly, many of the programs that are induced by injury in Aplysia are induced also by conditions that elicit cellular correlates of learning (Walters et al., 1991; Alberini et al., 1994; Noel et al., 1995). This implies that there is a convergence of the intracellular pathways for injury and learning (Walters and Ambron, 1995; Ambron and Walters, 1996), and some positive axonal signals might be common to both processes.

A $97 \mathrm{kDa}$ axoplasmic protein, which behaves like a positive injury signal because it is transported away from the site of a crush injury, features a nuclear localization sequence (NLS) (Ambron et

Received March 21, 1997; revised April 11, 1997; accepted April 1, 1997.

This work was supported by Graduate Training Grant for Careers in Molecular Ophthalmology 5T32EY07105 (K.T.), National Institutes of Health Grant NS-22150 (R.T.A.), and institutional funding from the Department of Biochemistry and Molecular Biophysics and American Cancer Society Grant IRG 177D (D.T.). We thank Drs. David Hirsch and Richard Axel for a helpful comments on this manuscript.

Aplysia were provided by the NCRR National Resource for Aplysia at the University of Miami under National Institutes of Health Grant RR10294.

Correspondence should be addressed to Dr. Richard T. Ambron, Department of Anatomy and Cell Biology, Black Building 1204, Columbia University Medical Center, West 168th Street, New York, NY 10032.

Copyright (C) 1997 Society for Neuroscience 0270-6474/97/174915-06\$05.00/0 al., 1996). The NLS can be recognized by the retrograde transport/nuclear import pathway that conveys proteins along the axon to the soma and into the nucleus (Ambron et al., 1992; Schmied et al., 1993). Given the possibility that an NLS is characteristic of positive signals, we are screening axoplasm for proteins that are can enter the nucleus (Ambron and Walters, 1996). One candidate is the transcription factor NF- $\kappa \mathrm{B}$, which is found in axons in rat brain (Kaltschmidt et al., 1993). NF- $\kappa \mathrm{B}$ consists of a p50 and a p65 subunit and has a rel homology domain comprised of an NLS and a region that recognizes $\kappa \mathrm{B}$ enhancer sites on DNA. Under resting conditions, the NLS and DNA binding regions are masked via an inhibitory protein, $\mathrm{I} \kappa \mathrm{B}$, and $\mathrm{NF}-\kappa \mathrm{B}$ resides in the cytoplasm in an (inactive) latent form (Baeuerle and Baltimore, 1988a; Beg et al., 1992; Liou and Baltimore, 1993; Thanos and Maniatis, 1995). The binding of an extracellular ligand to a surface receptor triggers the degradation of $\mathrm{I} \kappa \mathrm{B}$ by proteasomes and the liberation of NF- $\kappa \mathrm{B}$ (Baeuerle and Baltimore, 1988b; Verma et al., 1995). The activated NF- $\kappa \mathrm{B}$ is then imported into the nucleus where it regulates transcription and is ultimately degraded by proteasomes (Cressman and Taub, 1994). Theoretically, activation of latent NF- $\kappa \mathrm{B}$ in the axon would expose the NLS, resulting in its transport back to the cell nucleus. NF- $\kappa \mathrm{B}$, then, has many of the properties predicted for a positive injury signal (Ambron et al., 1992; Kaltschmidt et al., 1993). The current experiments were undertaken to determine whether NF- $\kappa \mathrm{B}$ is present in axons of the marine mollusc Aplysia and to see how it responds to injury.

\section{MATERIALS AND METHODS}

Nerve crush was performed essentially as described (Ambron et al., 1995). Aplysia californica (150-250 gm; Marinus, Venice, California) were anesthetized with isotonic $\mathrm{MgCl}_{2}$, and the body wall was incised through the foot. Care was taken not to disturb the nerves that exit from the bilateral pair of pedal ganglia; these pedal nerves provide sensory and motor information to the mid- and posterior body wall. The $\mathrm{MgCl}_{2}$ was 
replaced with artificial seawater (ASW), and all of the nerves on one side were crushed with forceps $\sim 2.5 \mathrm{~cm}$ from the ganglion. This effectively axotomizes the neurons in the pleural sensory cluster (Walters et al., 1983). The contralateral nerves served as controls (see text).

Axoplasm was extruded from nerve segments into ASW at $4^{\circ} \mathrm{C}$ (Sherbany et al, 1979, 1984: Schmied et al., 1993). PMSF was added to a final concentration of $1 \mathrm{mM}$. After centrifugation at $16,000 \times g$ to remove large organelles, the supernatant was removed and diluted with an equal volume of buffer (10 mm Tris- $\mathrm{HCl}, \mathrm{pH}$ 7.5, $1 \mathrm{~mm}$ EDTA, 5\% glycerol). The supernatant was then analyzed by Electrophoretic Mobility Shift Assay (EMSA). Nerve segments were homogenized on ice in binding buffer without NP-40 and were centrifuged at $16,000 \times g$. The supernatant was removed, and NP-40 was added to $0.1 \%$.

The effects of serotonin (5-HT) treatment were measured by either exposing the entire animal to $250 \mu \mathrm{M} 5-\mathrm{HT}$ in ASW at $15^{\circ} \mathrm{C}$ for $2 \mathrm{hr}$ (Alberini et al., 1994) or by exposing half of a dissected animal to $20 \mu \mathrm{M}$ 5-HT for 2 hr (Dale et al., 1987; Emptage and Carew, 1993), whereas the other half served as a control. Nerve segments were removed rapidly from the animals and homogenized immediately as described above.

EMSA and the preparation of the radiolabeled probes were as described (Baeuerle and Baltimore, 1988b) except that each reaction contained $1 \mu \mathrm{g}$ of poly $\mathrm{dI}-\mathrm{dC}$. The $\kappa \mathrm{B}$ enhancer sequence from the interferon $-\beta$ gene enhancer element $(-65$ to -54 ; PRDII $)=$ TCGACCGAGTGGGAAATTCCTCTG and the $\kappa \mathrm{B}$ site from the major histocompatibility complex I gene promotor $(\mathrm{H} 2)=$ TCGACCGAGT $G G$ GAATCCCCTCTG. PRDIV (another enhancer sequence that does not contain a $\kappa \mathrm{B}$ site) $=$ TAAATGACATAGGAAAACTGGG (Liou and Baltimore, 1993). The AP-1 oligonucleotide = CTAGATGACT $C A \mathrm{GCGCT}$, and the CRE = CTAGATCCCATGGCCGTCATACTGT GACGTCTTT (Kaang et al., 1993).

Nuclei were prepared from neurons of the pleuro-pedal ganglia of several animals as described (Dignam et al., 1983), except that buffer C was made iso-osmolar using $\mathrm{NaCl}$ and the final dialysis step was omitted. Nuclear extracts were preabsorbed for $30 \mathrm{~min}$ on ice with recombinant $\mathrm{I} \kappa \mathrm{B}-\alpha$. The I $\kappa \mathrm{B}-\alpha$ gene was cloned into a prokaryotic expression plasmid and isolated by affinity chromatography using Ni-NTA resin.

Sensory clusters from pleural-pedal ganglia with crushed peripheral nerves and contralateral control clusters were dissected in $70 \%$ propylene glycol in ASW at $-20^{\circ} \mathrm{C}$. Individual clusters were washed once in ice-cold PBS and transferred to tubes containing binding buffer. Samples were sonicated briefly and frozen at $-70^{\circ} \mathrm{C}$. Protein concentration was normalized, and EMSA was performed as described above.

\section{RESULTS}

\section{Aplysia neurons contain an NF- $\kappa$ B}

We used an EMSA to look for proteins in Aplysia neurons that bind to $\kappa \mathrm{B}$ DNA sequences. Two proteins in nuclear preparations recognized a radiolabeled probe containing the $\kappa \mathrm{B}$ sequence from the human interferon- $\beta$ gene enhancer element (PRDII) (Fig. $1 A$, lane 1$)$. The higher molecular weight protein migrated with mammalian NF- $\kappa \mathrm{B}$ (p50/p65), and its binding to the probe was not affected by PRDIV (lane 2), an ATF-2 enhancer sequence from the same gene. The binding was inhibited efficiently by nonradioactive oligonucleotides containing $\mathrm{H} 2$, the $\kappa \mathrm{B}$ site from the major histocompatibility complex I gene promotor (lane 3). The $\mathrm{H} 2$ and PII consensus $\kappa \mathrm{B}$ regions differ by three oligonucleotides (see Materials and Methods). The other protein was not always present, and its binding was not blocked by an excess of either $\mathrm{H} 2$ or PRDIV.

The protein in the nucleus that bound to the $\kappa \mathrm{B}$ probes was constitutively active. Because the p65 subunit of activated NF- $\kappa \mathrm{B}$ binds to the inhibitory protein $\mathrm{I} \kappa \mathrm{B}-\alpha$ (Liou and Baltimore, 1993), we investigated the effects of preincubating nuclear extracts with recombinant mammalian $\mathrm{I} \kappa \mathrm{B}-\alpha$. As shown in Figure $1 B$ (lanes $1-3)$, the binding activity was reduced in a dose-dependent manner. There was no reduction in binding if BSA or other nonspecific proteins were added (data not shown). Conversely, the I $\kappa \mathrm{B}-\alpha$ did not affect the binding of nuclear proteins to an AP-1 probe (lanes 4-6).

\section{Two forms of $\kappa \mathrm{B}$ binding are present in axoplasm}

To determine whether any $\kappa \mathrm{B}$ binding proteins are present in axons, we performed EMSAs on axoplasm extruded from pedal nerves to the body wall and found a protein that recognized the PII probe (Fig. 1C, lane 1). We also assayed the sheath that remains after extrusion (lane 2). Calculations based on density scans of the two lanes revealed that $62 \%$ of the total $\kappa \mathrm{B}$ binding in the nerves was in the extruded axoplasm. Because $\sim 65 \%$ of axoplasm is extruded from nerves by our procedure (Sherbany et al., 1984), most of the protein that binds to the $\kappa \mathrm{B}$-probes is probably in axons. In contrast, when we examined the distribution of other transcription factors in these same nerves, we found that the axoplasm contained only $19 \%$ of the total AP-1 binding (lanes $3,4)$ and an average of $24 \%$ for the three CRE oligonucleotidebinding activities identified previously by Dash et al., (1990) (lanes $5,6)$. This is consistent with these factors being in the glial cells and connective tissues that remain after extrusion.

We found that as with the factor in the nucleus, the binding of the axoplasmic protein to $\kappa \mathrm{B}$ probes was inhibited by excess cold $\mathrm{H} 2$ (Fig. 1D, lane 3), but not by PRDIV (lane 2) oligonucleotides. The binding was diffuse, however, suggesting that the protein was being degraded during the extrusion procedure. To avoid this possibility, we analyzed fractions from intact nerve segments that were rapidly excised from the animal. The $\kappa \mathrm{B}$ binding in the gel was now much more discrete (Fig. $1 E$, lane 1 ).

The data obtained above were consistent with the activity in the nucleus and axoplasm being attributable to an NF- $\kappa$ B-like protein rather than to one of the other rel homology proteins. It would be unusual to find an active extranuclear form of NF- $\kappa \mathrm{B}$, however, because it is the latent form of the factor that typically resides in the cytoplasm (but see Kaltschmidt et al., 1993). To determine whether a latent $\kappa \mathrm{B}$ activity is also present in axons, we exposed nerve extracts to deoxycholate (DOC). This detergent dissociates $\mathrm{NF}-\kappa \mathrm{B}$ from $\mathrm{I} \kappa \mathrm{B}$ and is a diagnostic measure of latent NF- $\kappa \mathrm{B}$ (Baeuerle and Baltimore, 1988a,b). DOC caused a dramatic increase in $\kappa \mathrm{B}$ binding, and the increase was associated with the same protein that was constitutively active (Fig. $1 E$, lanes 1,2 ). Furthermore, the response mimicked that of vertebrate NF- $\kappa \mathrm{B}$ (Baeuerle and Baltimore, 1988a,b) in that the binding was activated by low levels of DOC (lanes 3,4) and was inhibited by higher levels (lane 5) unless additional NP-40 was also included (lane 6). The NP-40 reduces the effective concentration of the DOC. We believe that these data warrant calling this protein a homolog of NF- $\kappa \mathrm{B}$, which we designate apNF- $\kappa \mathrm{B}$.

\section{ApNF- $\kappa B$ is affected rapidly by axon injury}

To examine the response of axonal apNF- $\kappa \mathrm{B}$ to injury, we crushed peripheral nerves to the body wall (Fig. $2 A$ ) and $20 \mathrm{hr}$ later, compared apNF- $\kappa \mathrm{B}$ activity in axoplasm extruded from the $0.5 \mathrm{~cm}$ crush segment with that in axoplasm extruded from a $0.5 \mathrm{~cm}$ segment of noncrushed nerve. Surprisingly, in all four experiments, each involving axoplasm pooled from two to three animals, there was no $\kappa \mathrm{B}$ binding in the crush axoplasm (Fig. $2 B$, lanes 1 , 2 ). In a separate experiment, a loss of activity was also seen when we examined nuclei isolated from neurons, the axons of which had been crushed $20 \mathrm{hr}$ earlier (Fig. 2B, lanes 3-5). As expected, DOC did not unmask any latent activity in the nucleus (lane 5).

The effects of injury on the axons were intriguing, because an extranuclear loss of NF- $\kappa \mathrm{B}$ activity had not been reported previously. Moreover, the loss occurred rapidly. In one series of experiments, we waited only 5 min after nerve crush before analyzing the nerve segments just proximal to the crush site and the con- 

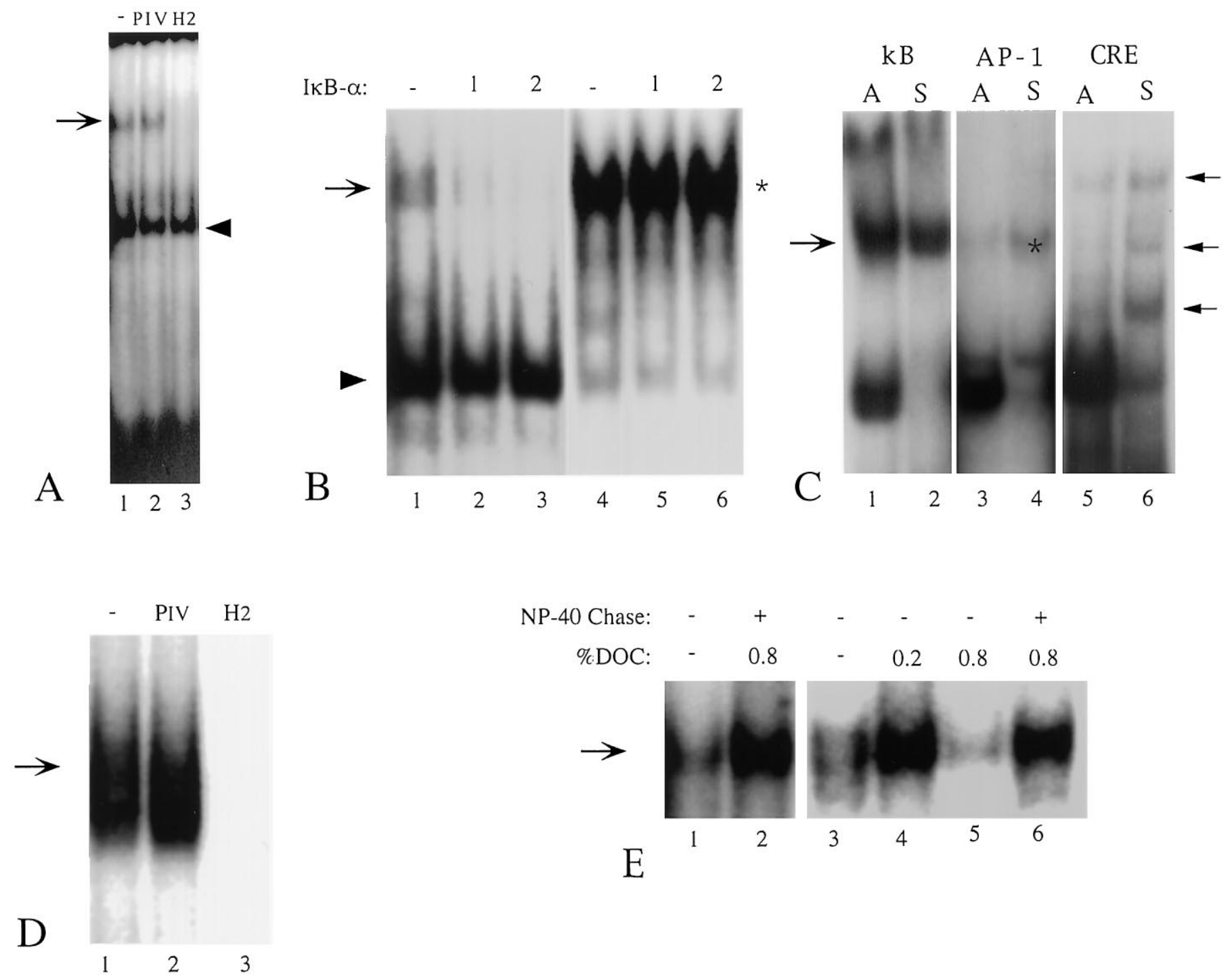

Figure 1. Characterization of Aplysia $\kappa \mathrm{B}$ binding; representative results from two to five experiments are shown. $A$, Radiolabled probes were added to nuclear extracts and after EMSA, DNA-binding complexes were visualized using radioautography. Radiolabeled probe PII was added to a nuclear extract from HeLa cells to determine the position of NF- $\kappa \mathrm{B}$ (p50/p65) (arrow). When radiolabeled PII was incubated with $5 \mu \mathrm{g}$ of a nuclear extract, two proteins were detected (lane 1). Binding of one of the proteins (arrow) to the probe was not competed by unlabeled oligonucleotide PIV (lane 2), but was efficiently blocked by H2 (lane 3). The other protein (arrowhead) was unaffected by the presence of competitor DNAs. $B$, Nuclear $\kappa$ B-DNA binding to radiolabeled PII (arrow, lane 1) was inhibited by $1 \mu \mathrm{g}$ (lane 2) and $2 \mu \mathrm{g}$ (lane 3) of recombinant mammalian I $\kappa \mathrm{B}-\alpha$. The other protein (arrowhead) was unaffected by $\mathrm{I} \kappa \mathrm{B}-\alpha$. In addition, binding to a radiolabeled AP-1 enhancer sequence (CTAGATGACTCAGCGCT; asterisk) was not affected by I $\kappa \mathrm{B}-\alpha$ at either concentration (lanes $4-6$ ). The portion of the film containing the unbound probe was removed in this and subsequent figures. $C$, The $\kappa \mathrm{B}$ binding was enriched in axoplasm extruded from the pedal nerves (lane 1, arrow) relative to that which remains in the sheath (lane 2). In contrast, most of the AP-1 (asterisk, lanes 3, 4) and CRE-binding (small arrows, lanes 5, 6) activities were found in the sheath. D, The $\kappa \mathrm{B}$ binding to PII in extruded axoplasm (lane 1) was not affected by excess PIV (lane 2), but was specifically disrupted by excess $\mathrm{H} 2$ oligonucleotide (lane 3 ). $E$, Latent $\kappa \mathrm{B}$ activity was unmasked when extracts from nerve segments were treated with DOC (lanes 1,2). The activity in the extracts was stimulated by a low concentration of DOC (lanes 3,4$)$, but was inhibited by $0.8 \%$ DOC (lane 5). Activity was recovered when excess DOC was removed by $0.85 \%$ NP-40 (lanes 2, 6).

tralateral noninjured control segments (Fig. $2 A$ ). Segments were used to minimize the manipulations before analysis. EMSAs from three experiments revealed an average $65 \%$ reduction in $\kappa \mathrm{B}$ binding activity (Fig. $2 C$ ). How far along the axon from the crush site does the loss of apNF- $\kappa \mathrm{B}$ extend? To address this issue, we waited $15 \mathrm{~min}$ after crush injury and analyzed two additional 0.5 cm segments, P1 and P2, located more proximally along each nerve (Fig. $2 A$ ). In all three experiments, there was no constitutive apNF $-\kappa \mathrm{B}$ binding at either the crush site (Fig. 2D, lane 2) or in either of the two proximal segments (lanes 3,4). The same result was obtained when we waited $45 \mathrm{~min}$ after crush (Fig. $2 D$, lanes $5-8)$.
One explanation for the loss of constitutive activity in the axon after injury would be a reassociation of apNF- $\kappa \mathrm{B}$ with $\mathrm{I} \kappa \mathrm{B}$. However, DOC treatment unmasked $<5 \%$ of the latent activity relative to the controls (Fig. 2E), meaning that nerve crush also caused a loss of the latent form.

Many axons in the pedal nerves originate from neurons in the pleural sensory cluster. The intact cluster is easy to isolate, and the response of these neurons to pedal nerve injury has been well studied (for review, see Ambron and Walters, 1996). To determine whether $45 \mathrm{~min}$ is sufficient time for apNF- $\kappa \mathrm{B}$ to be lost in the cell body, we crushed all of the pedal nerves $1 \mathrm{~cm}$ from the ganglion on one side of the animal. This effectively axotomizes all 

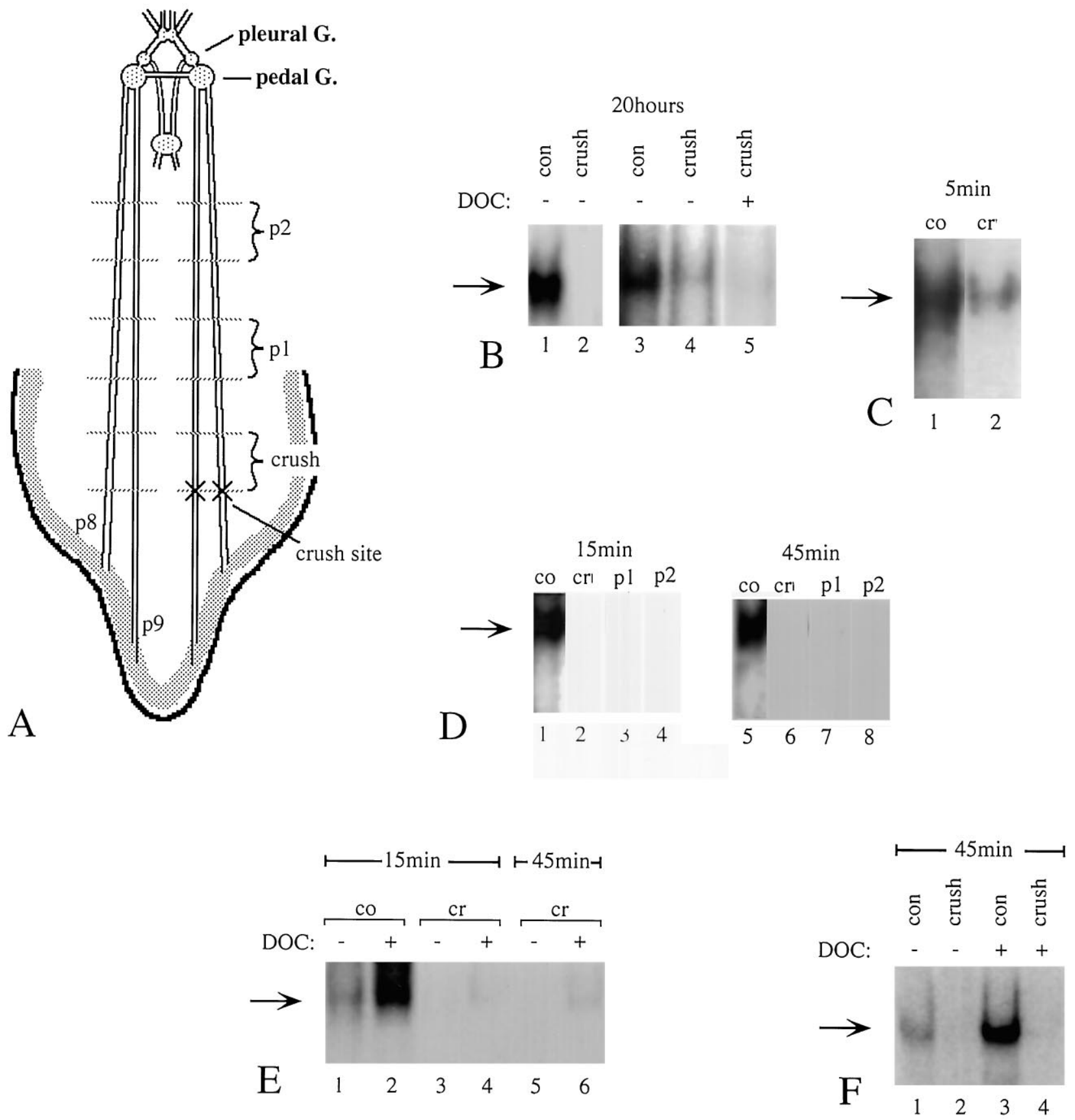

Figure 2. Loss of apNF- $\kappa$ B DNA-binding activity after nerve crush. $A$, Schematic showing the crush site on nerves p8 and $\mathrm{p} 9$ to the tail. Crush refers to the nerve segment adjacent to the crush site, and P1 and P2 refer to segments more proximal. Each segment was $0.5 \mathrm{~cm}$ long. Segments of equal size on the contralateral nerves served as controls. Extruded axoplasm, or intact segments, from two to three animals was pooled for each experiment, and representative results are shown. Tissue fractions were assayed for $\kappa$ B binding by EMSA using the PII probe. $B$, Soluble axoplasm (10 $\mu \mathrm{g})$ from control and crush segments was analyzed $20 \mathrm{hr}$ after nerve crush. Constitutive apNF- $\kappa \mathrm{B}-\mathrm{DNA}$ binding was present in the control (lane 1) but absent in the crush segment (lane 2). Activity was reduced in nuclear extracts $(10 \mu \mathrm{g})$ pooled from the pleuro-pedal neurons of four animals $20 \mathrm{hr}$ after nerve crush, relative to that in control nuclear extracts (lanes 3,4), and activity was not recovered with DOC (lane 5). All of the pedal nerves were crushed in the experimental and none in the control. $C$, Five minutes after crush injury, $4 \mu \mathrm{g}$ of protein from the segments was analyzed. Comparisons showed a loss of apNF- $\kappa \mathrm{B}$ activity in the crush segments (lane 2) relative to controls (lane 1). $D$, To examine the loss of apNF- $\kappa \mathrm{B}$ along the axon after crush injury, $4 \mu \mathrm{g}$ of protein from the crush, P1, P2, and control segments was analyzed at 15 min (lanes 1-4) and 45 min (lanes 5-8). Constitutive apNF- $\kappa \mathrm{B}$ binding was present in the controls 15 min (lanes 1) and 45 min (lane 5) after injury, but was absent in the crush (lanes 2, 6), P1 (lanes 3, 7), and P2 (lanes 4, 8) segments at both times. $E$, DOC treatment of $4 \mu \mathrm{g}$ of extract from control segments unmasked latent activity (lanes 1,2$)$ but had no effect on the crush segments 15 $\min$ (lanes 3, 4) or $45 \mathrm{~min}$ (lanes 5, 6) after injury. F, Forty-five minutes after nerve crush, the sensory cell cluster from the crush-injured and control sides were excised and homogenized, and $600 \mathrm{ng}$ of protein was analyzed. There was a dramatic loss of apNF- $\kappa \mathrm{B}($ lanes 1,2$)$ that was not recovered by DOC (lanes 3, 4). 


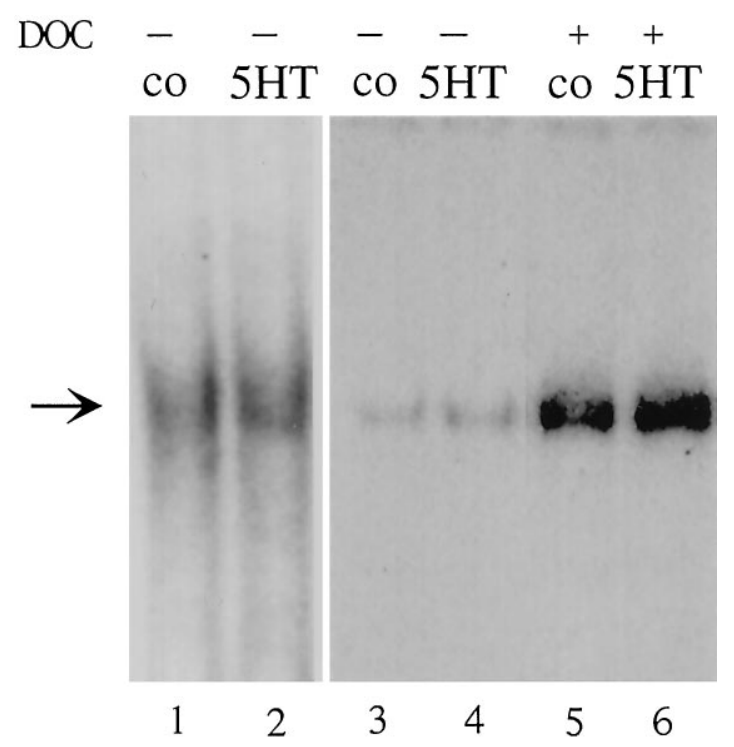

Figure 3. 5-HT does not affect apNF- $\kappa \mathrm{B}$ activity in the axon. To assess the effect of 5-HT on apNF- $\kappa$ B activity, an intact animal was exposed to $250 \mu \mathrm{M}$ 5-HT for $2 \mathrm{hr}$. Nerve segments $(2 \mathrm{~cm})$ were homogenized, and $6 \mu \mathrm{g}$ of the extract was removed for EMSA using the PII probe. An equal amount of extract from segments from an animal incubated in seawater was used as a control. There was no difference in binding between the animal treated with the 5-HT (lane 2) and the control (lane 1). Likewise, exposure of half of the nervous system in situ to $20 \mu \mathrm{M} 5-\mathrm{HT}$ for $2 \mathrm{hr}$ did not alter apNF- $\kappa$ B activity in $4 \mu \mathrm{g}$ of extracts (lane 4 ) relative to a similar extract from the contralateral control half incubated for the same time in seawater (lane 3). There was also no difference in the latent form (lanes 5, 6).

of the sensory neurons (Walters et al., 1983). The nerves on the contralateral side were left untouched. Forty-five minutes later, the sensory clusters were isolated and examined for apNF- $\kappa$ B activity. Three experiments were performed with variable results. In one experiment, there was no change, in another, there was a $25 \%$ reduction in binding, and in the third, there was a complete loss of activity (Fig. $2 F$, lanes 1,2 ). We treated samples from the third experiment with DOC, but as with the crushed axons, there was no activation of the latent form (lanes 3, 4).

\section{5-HT does not affect apNF- $\mathbf{B}$}

Many of the changes induced in Aplysia neurons by axon injury (Walters et al., 1991; Clatworthy and Walters, 1994; Noel et al., 1995; Steffensen et al., 1995) are also seen after exposing the nervous system to levels of 5-HT that induce synaptic facilitation, a cellular correlate of behavioral sensitization (Bailey and Kandel, 1993; Byrne et al., 1993; Kaang et al., 1993; Alberini et al., 1994). We used two different protocols to determine how 5-HT affects apNF- $\kappa$ B. First, we exposed the intact animal to $250 \mu \mathrm{M} 5$-HT for $2 \mathrm{hr}$ (Alberini et al., 1994) but did not detect any changes in either the activity or the distribution of apNF- $\kappa \mathrm{B}$ (Fig. 3, lanes 1, 2). Likewise, exposure of half of an otherwise intact nervous system in situ to $20 \mu \mathrm{M}$ 5-HT (Dale et al., 1987; Emptage and Carew, 1993) had no affect on the constitutively active (lanes 3,4) or latent forms (lanes 5, 6) of apNF- $\kappa \mathrm{B}$ when compared with contralateral controls.

\section{DISCUSSION}

We have identified a $\kappa \mathrm{B}-\mathrm{DNA}$-binding protein in Aplysia neurons that has the properties of a homolog of vertebrate NF- $\kappa$ B. Thus, (1) it migrates with authentic NF- $\kappa \mathrm{B}$ on EMSAs; (2) it recognizes oligonucleotide probes containing two different consensus $\kappa \mathrm{B}$ sequences; (3) the binding to the probes is blocked by recombinant mammalian $\mathrm{I} \kappa \mathrm{B}$, which binds specifically to the p65 subunit of NF- $\kappa \mathrm{B}$; (4) it is present in an active form in the nucleus and in a latent form outside of the nucleus; and (5), the latent form is activated by the same DOC treatments as vertebrate NF- $\kappa \mathrm{B}$. We were unable to supershift the DNA-apNF- $\kappa \mathrm{B}$ complex using antibodies to mammalian NF- $\kappa \mathrm{B}$. However, other Aplysia transcription factors that are the functional equivalent of the vertebrate forms also exhibit only partial sequence homology (Alberini, 1994; Bartsch et al., 1995).

Our finding of apNF- $\kappa \mathrm{B}$ in axoplasm corroborates the earlier report by Kaltschmidt et al., (1993) and raises the important issue as to what this transcription factor might be doing in the axon. One possibility is that it passively enters the axon with the bulk of axoplasm and that its presence has no functional consequence. This is unlikely, given that the export of proteins from the cell soma into the axon is selective (Grafstein and Forman, 1980) and would be even less likely for proteins that are destined to enter the nucleus. We found little, if any, of the transcription factors that recognize the AP-1 and CRE enhancer sites in axoplasm, indicating that the entry of NF- $\kappa \mathrm{B}$ into the axon is selective.

A clue as to the function of NF- $\kappa \mathrm{B}$ in the axon might be its unique ability to respond to external cues by undergoing a transition from the cytoplasmic to the nuclear compartment. This transition occurs because the $\mathrm{I} \kappa \mathrm{B}$ is removed, activating the NF- $\kappa \mathrm{B}$ and exposing the NLS. Both we and Kaltschmidt et al. (1993) found an active NF- $\kappa \mathrm{B}$ in axons. This is significant because if the NLS is exposed, as expected, then the NF- $\kappa \mathrm{B}$ would have access to a pathway that retrogradely transports proteins through the axon and into the cell body, where they are subsequently imported into the nucleus (Ambron et al., 1992; Schmied et al., 1993). Indeed, the NLS of the p65 subunit of NF- $\kappa$ B (-KKRK-) (Beg et al., 1992) closely resembles that of the SV40 large T antigen (-KKKRK-), which is one of the proteins that uses this pathway. Axonal NF- $\kappa \mathrm{B}$ could therefore participate in a communication system that links events in the axon and synapse to the biosynthetic machinery in the cell nucleus (Ambron et al., 1992; Kaltschmidt et al., 1993). As a first step in determining the validity of this idea, we are trying to identify events in the axon that initiate the conversion of the latent to the active form.

One of the first manipulations that we tried was to injure the axon. Rather than activate the apNF- $\kappa \mathrm{B}$, injury caused a rapid and dramatic loss of DNA binding. Because we are measuring binding, the factor could be present after nerve crush, but in a form that cannot bind DNA. Activity could then be recovered by a reactivation mechanism rather than by de novo synthesis in the cell body. We eliminated an injury-induced reassociation with $\mathrm{I} \kappa \mathrm{B}$ by showing that activity was not restored with DOC. Alternatively, injury could cause the degradation of apNF- $\kappa$ B. Previous studies found that other proteins at the crush site remain intact (Ambron et al., 1995), indicating that the loss of apNF- $\kappa \mathrm{B}$ is selective. A good candidate is the ubiquitin/proteasome pathway, which is present in axoplasm (Chain et al., 1995), degrades NF- $\kappa$ B after hepatectomy (Cressman and Taub, 1994), and is capable of eliminating its substrates very rapidly (Kawahara and Yokosawa, 1994). Moreover, proteasomes can be activated by $\mathrm{Ca}^{2+}$ (Kawahara and Yokosawa, 1994). Studies of Aplysia neurons in vitro have shown that the levels of intracellular $\mathrm{Ca}^{2+}$ increase at the crush site (Ziv and Spira, 1993) and probably along the axon in response to action potentials triggered by the injury.

Still to be explained is why apNF- $\kappa \mathrm{B}$ DNA binding was not always destroyed as rapidly in the soma of the sensory cells. 
Perhaps $\mathrm{Ca}^{2+}$ entry and proteasome activity in the soma and nucleus is subject to more complex regulation than in axoplasm. For example, synaptic inputs from other cells that have been injured could mitigate the influence of injury spikes invading from the axon (Trudeau and Castellucci, 1992). The loss of apNF- $\kappa$ B binding is interesting because it mimics the effects of a targetderived "negative" signal. Instead of the injury physically preventing the signal from reaching the cell body, however, the crush actually causes the loss of the signal.

There are many similarities in the molecular cascades elicited in Aplysia sensory neurons by injury and learning, and one important site of convergence is the transcription factor apC/EBP (Alberini et al., 1994). Identifying sites of divergence can also be informative, and we have been searching for signals that distinguish between these two processes (Walters and Ambron, 1995; Ambron and Walters, 1996). ApNF- $\kappa$ B might be such a signal because it is not affected by levels of serotonin that induce the molecular events that underlie sensitization, which is an elementary form of learning. If apNF- $\kappa \mathrm{B}$ is an injury signal, then our data suggest that it regulates processes that distinguish regeneration from learning, the most obvious being those related to growth. Regeneration requires the formation of a new axon and synapse (Steffensen et al., 1995), whereas memory consolidation involves the expansion of already existing terminals (Bailey and Chen, 1988; Bailey and Kandel, 1993; Bartsch et al., 1995). The rapid removal of apNF- $\kappa \mathrm{B}$ after crush injury in Aplysia could be involved in regeneration of the distal axonal arbor.

\section{REFERENCES}

Alberini CM, Ghirardi M, Metz R, Kandel ER (1994) C/EBP is an immediate-early gene required for the consolidation of long-term facilitation in Aplysia. Neuron 76:1099-1114.

Ambron RT, Walters ET (1996) Priming events and retrograde injury signals: a new perspective on the cellular and molecular biology of nerve regeneration. Mol Neurobiol 13:61-79.

Ambron RT, Schmied R, Huang CC, Smedman M (1992) A signal sequence mediates the retrograde transport of proteins from the axon periphery to the cell body and then into the nucleus. J Neurosci 12:2813-18.

Ambron RT, Dulin MF, Zhang X-P, Schmied R, Walters ET (1995) Axoplasm enriched in a protein mobilized by nerve injury induces memory-like alterations in Aplysia neurons. J Neurosci 15:3440-3446.

Ambron RT, Zhang X-P, Gunstream JD, Povelones M, Walters ET (1996) Intrinsic injury signals enhance growth, survival, and excitability of Aplysia neurons. J Neurosci 16:7469-7477.

Baeuerle PA, Baltimore D (1988a) Activation of DNA-binding activity in an apparently cytoplasmic precursor of the NF- $\kappa$ B transcription factor. Cell 53:211-217.

Baeuerle PA, Baltimore D (1988b) I $\kappa$ B: a specific inhibitor of the NF- $\kappa$ B transcription factor. Science 242:540-546.

Bailey CH, Kandel ER (1993) Structural changes accompanying memory storage. Annu Rev Physiol 55:397-426.

Beg AA, Ruben SM, Scheinman RI, Haskill S, Rosen CA, Baldwin Jr AS (1992) I $\kappa$ B interacts with the nuclear localization sequences of the subunits of NF- $\kappa$ B: a mechanism for cytoplasmic retention. Genes Dev 6:1899-1913.

Byrne JH, Zwartjes R, Homayouni R, Critz SD, Eskin A (1993) Roles of second messenger pathways in neuronal plasticity and in learning and memory. Adv Second Messenger Phosphoprotein Res 27:47-108.

Chain DG, Hegde AN, Yamamoto N, Liu-Marsh B, Schwartz JH (1995) Persistent activation of cAMP-dependent protein kinase by regulated proteolysis suggests a neuron-specific function of the ubiquitin system in Aplysia. J Neurosci 15:7592-7603.

Clatworthy A, Walters ET (1994) Comparative analysis of hyperexcitability and synaptic facilitation induced by nerve injury in two populations of mechanosensory neurones of Aplysia californica. J Exp Biol 190:217-238.
Cressman DE, Taub R (1994) Physiologic turnover of nuclear factor $\kappa$ B by nuclear proteolysis. J Biol Chem 269:26594-26597.

Dale N, Kandel ER, Schacher S (1987) Serotonin produces long-term changes in the excitability of Aplysia sensory neurons in culture that depend on new protein synthesis. J Neurosci 7:2232-2238.

Dash PK, Hochner B, Kandel ER (1990) Injection of cAMP-responsive element into the nucleus of Aplysia sensory neurons blocks long-term facilitation. Nature 345:718-721.

Dignam JD, Lebovitz RM, Roeder RG (1983) Accurate transcription initiation by RNA polymerase II in a soluble extract from isolated mammalian nuclei. Nucleic Acids Res 11:1475-1489.

Emptage NJ, Carew TJ (1993) Long-term synaptic facilitation in the absence of short-term facilitation in Aplysia neurons. Science 262:253-256.

Fawcett JW, Keynes RJ (1990) Peripheral nerve regeneration. Annu Rev Neurosci 13:43-60.

Grafstein B, Forman DS (1980) Intracellular transport in neurons. Physiol Rev 60:1167-1283.

Kaang BK, Kandel ER, Grant SGN (1993) Activation of cyclic AMPresponsive genes by stimuli that produce long-term facilitation in Aplysia sensory neurons. Neuron 10:427-435.

Kaltschmidt C, Kaltschmidt B, Baeuerle PA (1993) Brain synapses contain inducible forms of the transcription factor NF- $\kappa$ B. Mechan Dev 43:135-147.

Kawahara H, Yokosawa H (1994) Intracellular calcium mobilization regulates the activity of $26 \mathrm{~S}$ proteasome during the metaphase-anaphase transition in the ascidian meiotic cell cycle. Dev Biol 166:623-633.

Lieberman AR (1971) The axon reaction: a review of the principal features of perikaryal responses to axon injury. Int Rev Neurobiol $14: 49-124$.

Liou HC, Baltimore D (1993) Regulation of the NF- $\kappa$ B/rel transcription factor and I $\kappa$ B inhibitor system. Curr Opin Cell Biol 5:477-487.

Noel F, Frost WN, Tian L-M, Colicos MA, Dash PK (1995) Recovery of tail-elicited siphon-withdrawal reflex following unilateral axonal injury is associated with ipsi- and contralateral changes in gene expression in Aplysia californica. J Neurosci 15:6926-6938.

Schmied R, Huang C-C, Zhang X-P, Ambron D, Ambron RT (1993) Endogenous axoplasmic proteins and proteins containing nuclear localization signal sequences use the retrograde axonal transport/nuclear import pathway in Aplysia neurons. J Neurosci 13:4064-4071.

Sherbany AA, Ambron RT, Schwartz JH (1979) Membrane glycolipids: regional synthesis and axonal transport in a single identified neuron of Aplysia californica. Science 203:78-81.

Sherbany AA, Ambron RT, Schwartz JH (1984) Characterization of glycolipids synthesized in an identified neuron of Aplysia californica. J Neurosci 4:1875-1883.

Skene JHP (1989) Axonal growth-associated proteins. Annu Rev Neurosci 12:127-156.

Steffensen I, Dulin MF, Walters ET, Morris CE (1995) Peripheral regeneration and central sprouting of sensory neurone axons in Aplysia californica following nerve injury. J Exp Biol 198:2067-2078.

Thanos D, Maniatis T (1995) NF- $\kappa$ B: a lesson in family values. Cell 80:529-532.

Titmus M, Faber D (1990) Axotomy induced alterations in the electrophysiological characteristics of neurons. Prog Neurobiol 35:1-51.

Trudeau L-E, Castellucci VF (1992) Contribution of polysynaptic pathways in the mediation and plasticity of Aplysia gill and siphon withdrawal reflex: evidence for differential modulation. J Neurosci 12:3838-3848.

Verma IM, Stevenson JK, Schwarz EM, Antwerp DV, Miyamoto S (1995) Rel/NF- $\kappa$ B/I $\kappa$ B family: intimate tales of association and dissociation. Genes Dev 9:2723-2735.

Walters ET, Ambron RT (1995) Long-term alterations induced by injury and by 5-HT in Aplysia sensory neurons: convergent pathways and common signals? Trends Neurosci 18:137-142.

Walters ET, Byrne JH, Carew TJ, Kandel ER (1983) Mechanoafferent neurons innervating tail of Aplysia. I. Response properties and synaptic connections J Neurophysiol 50:1522-1542.

Walters ET, Alizadeh H, Castro EA (1991) Similar neuronal alterations induced by axonal injury and learning in Aplysia. Science 253:797-799.

Ziv NE, Spira ME (1993) Spatiotemporal distribution of Ca2+ following axotomy and throughout the recovery process of cultured Aplysia neurons. Eur J Neurosci 5:657-668. 